\title{
Massive pneumoperitoneum following colonoscopic sigmoid perforation
}

\author{
Khalil EIGendy, Amro Salem
}

Department of Colorectal Surgery, King Fahad Specialist Hospital Dammam, Dammam, Eastern Province, Saudi Arabia

\section{Correspondence to}

Dr Khalil ElGendy,

k.m.elgendy@gmail.com

Accepted 6 April 2014

\section{DESCRIPTION}

An 82-year-old man presented with a change in bowel habits and bleeding per rectum with no history of any associated comorbidities. On examination, there was palpable thickening of the rectum. Investigations showed normal carcinoembryonic antigen level and contrast CT revealed a thickening of the rectal wall with no evidence of metastasis (figure 1). The ECG revealed bifascicular heart block, but with normal functions on echocardiography. Colonoscopy was performed to confirm the diagnosis and to take a histopathological specimen. Biopsy was taken from the mass and during trials to pass through the sigmoid to screen the rest of the colon, unfortunately, there was marked difficulty passing the sigmoid region with looping and multiple attempts that ended in perforation.

$\mathrm{X}$-rays of the abdomen in supine and sitting positions, showing the massive pneumoperitoneum with its classic signs described (figure 2A, B). The patient suffered from respiratory distress and underwent shock. Immediate resuscitation was followed by transfer to the operating theatre and exploration was performed. It revealed a large colonic perforation, more than half of the circumference with no gross contamination of the

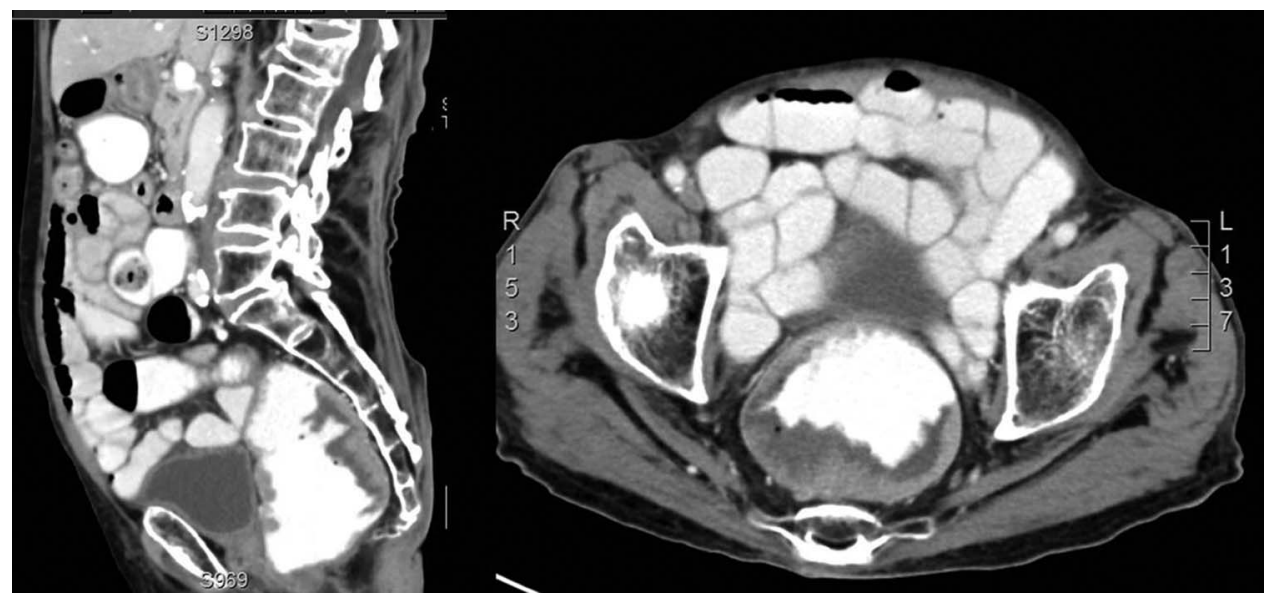

Figure $1 \mathrm{CT}$ with contrast, axial and sagittal section showing thickening of the rectal wall.

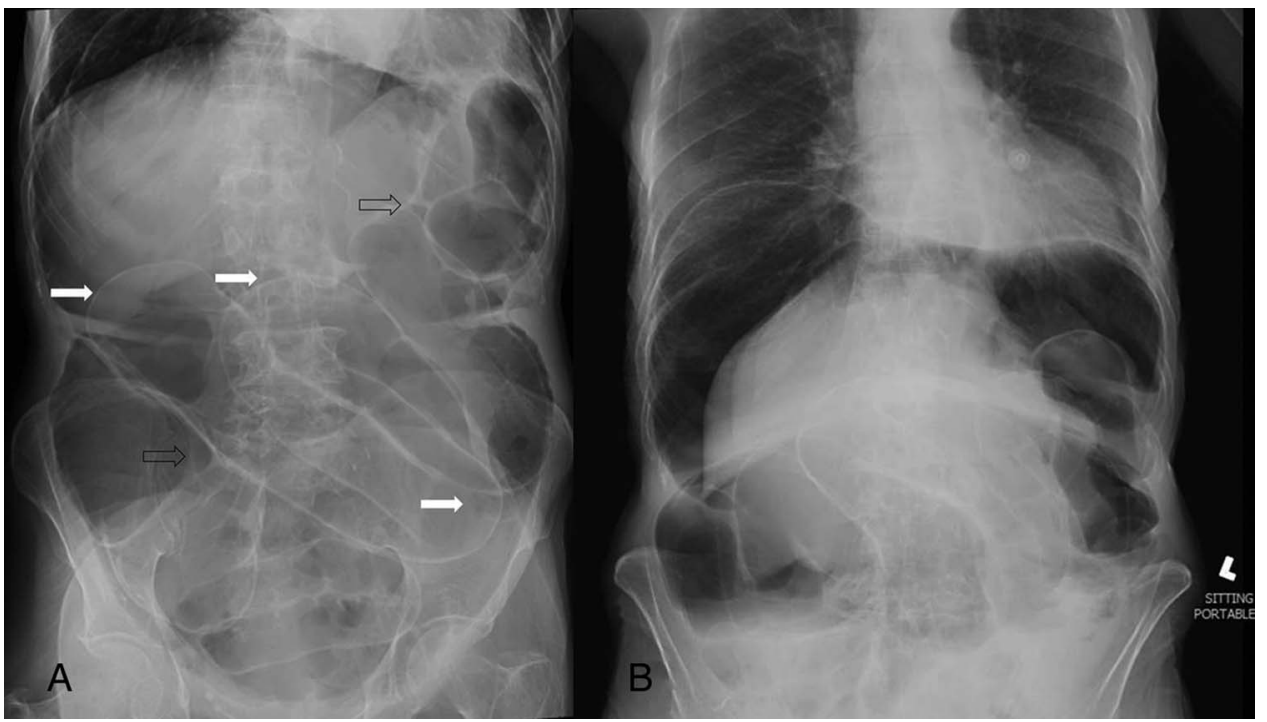

To cite: ElGendy K, Salem A. BMJ Case Rep Published online: [please include Day Month Year] doi:10.1136/bcr-2014204012

Figure 2 Plain X-ray of the abdomen (supine (A) and erect (B)) showing massive pneumoperitoneum. Solid arrows showing Rigler's sign and empty arrows showing the triangular sign. 


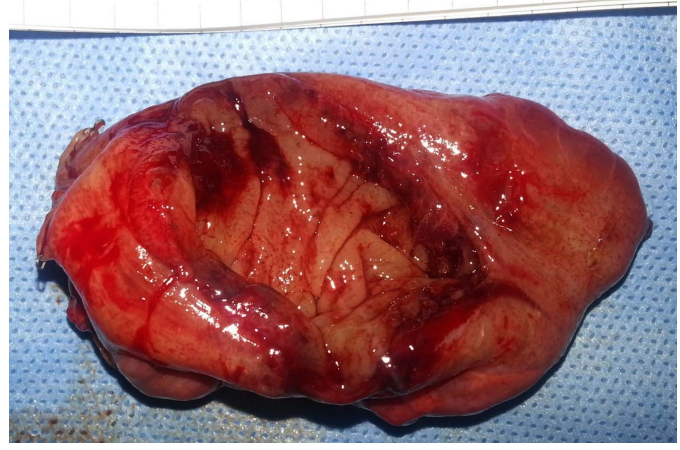

Figure 3 The surgical specimen of the sigmoid showing the large perforation $(4 \mathrm{~cm})$ at antimesentric border.

peritoneum (figure 3). The decision was to perform Hartmanns' procedure, resecting the perforated segment, closing the distal stump and performing end colostomy. The biopsy revealed tubovillous adenoma. The patient had an extended postoperative intensive care unit stay with prolonged intubation, which ended in respiratory failure with further compromise of the cardiac functions. The patient died after approximately 2 months.

The incidence of colonic perforation may be around $0.016-$ $0.02 \%$, but may reach $5 \%$ in the colonoscopies. ${ }^{1}$ The commonest site of perforation is the sigmoid where it may reach $65 \%$ which might be caused by the sharp angle of the junctions with either the rectum or the descending colon (which is the case in this patient) and great mobility of the sigmoid. The loop formation with powerful introduction of the scope can lead to the antimesenteric perforation by the endoscopic shaft. Other causes of sigmoid perforation can be related to the diverticulosis and pelvic adhesions. Patients may be diagnosed immediately, within $24 \mathrm{~h}$ or beyond 1 day.

Most of the patients need surgical intervention; however, conservative and endoscopic management (eg, clipping) is possible in selected cases. Many surgical techniques can be offered, which are dependent on different factors including: diameter of perforation, time between the incident and exploration, degree of peritoneal contamination and general condition. ${ }^{2}$ Open or laparoscopic repair of the perforated segment is the commonest procedure which might be accompanied by proximal diverting stoma. Resection with primary anastomosis or Hartmann's procedure can also be additional options. ${ }^{3}$ Presence of higher American Society of Anaesthesiologists class (III or IV) or heart diseases was significantly associated with mortality which is the state in the presented case. ${ }^{3}$

The classic radiological signs of a massive pneumoperitoneum may include: presence of free air in the right hypochondrium with hyperlucency of the liver (the commonest), the Rigler's sign (double wall), football sign (outline of the entire abdomen), triangle sign and visible ligamentum teres. ${ }^{4}$

\section{Learning points}

- Colonoscopy is an important tool for diagnosing colonic tumours, obtaining histopathological specimens and therapeutic options (eg, stenting), yet there are associated complications.

- The commonest site of endoscopic perforation of the colon is the sigmoid region due to many anatomical and pathological features.

- Colonic perforations as complications of the endoscopic procedure may range from trivial subclinical events that can be managed conservatively to serious events that may necessitate emergency laparotomy, with different surgical options and techniques, the decision of which is dependent on many important factors.

Contributors KE was involved in data collection, literature review and discussion of the manuscript. AS was involved in revision, informed consent and final approval of the manuscript.

Competing interests None.

Patient consent Obtained.

Provenance and peer review Not commissioned; externally peer reviewed.

\section{REFERENCES}

1 Lohsiriwat V. Colonoscopic perforation: incidence, risk factors, management and outcome. World J Gastroenterol 2010;16:425-30.

2 Tarnowski W, Kamiński P, Krześniak N, et al. Management of colonoscopic perforations of large bowel. Pol Merkur Lekarski 2011;31:340-4.

3 Tam MS, Abbas MA. Perforation following colorectal endoscopy: what happens beyond the endoscopy suite? Permanente J 2013;17:17-21.

4 Hull AM, Buckley P, Wills B. Massive pneumoperitoneum. West J Emerg Med 2010;11:92.

\footnotetext{
Copyright 2014 BMJ Publishing Group. All rights reserved. For permission to reuse any of this content visit

http://group.bmj.com/group/rights-licensing/permissions.

BMJ Case Report Fellows may re-use this article for personal use and teaching without any further permission.

Become a Fellow of BMJ Case Reports today and you can:

- Submit as many cases as you like

- Enjoy fast sympathetic peer review and rapid publication of accepted articles

- Access all the published articles

- Re-use any of the published material for personal use and teaching without further permission

For information on Institutional Fellowships contact consortiasales@bmjgroup.com

Visit casereports.bmj.com for more articles like this and to become a Fellow
} 